\section{Talking about their g-g-generation}



\author{
Conversations in Genetics: an Oral \\ History of our Intellectual Heritage \\ in Genetics, Vols 1 and 2 \\ Edited by Rochelle Easton Esposito
}

The Genetics Society of America •

2004, 2005

$\$ 120$ for 5 DVDs; $\$ 30$ for 1 DVD

Nathaniel Comfort

Interviewing is a technique for creating a historical document. When historians interview for their own research, they take on the unusual role of helping to create the documents that they then analyse and interpret. The historian is, of course, less knowledgeable than the interviewee about the subject matter. A good interviewer uses this fact to elicit anecdotes and explanations that give meaning and context to the subject. But the historian's relative ignorance may also mean that they lack the technical or cultural knowledge to ask the crucial questions. Another approach is the peer interview, in which a professional colleague asks the questions. A peer interviewer may achieve a level of intimacy with both the interviewee and the subject matter that a historian or trained interviewer cannot. But that intimacy can also make the interview cryptic, like an old married couple finishing one another's sentences. Furthermore, for lack of experience, peer-interviewers often commit errors - leading the subject, interrupting the subject, being inconsistent from interview to interview, and so forth - that practiced interviewers learn to avoid.

As its title suggests, Conversations in Genetics is a series of peer interviews. The ten DVDs each contain a video interview with a leading figure in genetics: Lee Hartwell, François Jacob, Ed Lewis, Arno Motulsky, Evelyn Witkin, James F. Crow, Seymour Benzer, Ira Herskowitz, Janet Rowley and Dan Lindsley. The interviewers - including Alfred Knudson, Mary-Claire King, Jasper Rine and Daniel Hartl - are distinguished researchers in their own right. The videos have a faculty-club feel: the campus legend chats comfortably with another luminary, while we eavesdrop from an adjacent table.

The pleasures of peer interviews are abundant here. It is delightful to see the mutual affection of $\mathrm{Al} \mathrm{Knudson}$ and Janet Rowley, or Lucy Shapiro's reverence for François Jacob. The interviews are all strong on the science. Daniel Hartl can ask his former supervisor Jim Crow about obscure papers that give a real sense of the span of his career. Rochelle Easton Esposito can keep pace with Lee Hartwell as he leads her through the intricacies of his pioneering work in cell-cycle genetics.

Nathaniel Comfort is in the Institute of the History of Medicine,

The Johns Hopkins University, 1900 East Momument Street, Baltimore,

MD 21205, USA.

e-mail: comfort@jhmi.edu
Yet the weaknesses of peer interviewing are also evident. In part, because the interviewers have no core question set, details of the subjects' childhoods, family lives and career paths are patchy. Lewis tells us where he was born and something about growing up; Jacob, however, seems to begin life in the army. The scientific discussions are often elliptical: Ira Herskowitz need not stop to explain the rudiments of yeast genetics to Jasper Rine, though an eavesdropper might wish for a quick review. Nevertheless, the videos contain many minor 'eureka' moments, such as Ed Lewis explaining that in the 1950 s, the fruit fly - now considered an ideal model organism for developmental biology — was thought useless for embryological work.

The selection of interview subjects is puzzling. At first, the roster appears to give even coverage across the discipline: there are two fly geneticists, two yeast geneticists, three microbial geneticists, and three human geneticists. This tracks the current emphasis of the Genetics Society of America, which produced the project - except for the human geneticists. There are other anomalies. The set contains no mouse geneticists, nor any plant geneticists, although the Genetics Society of America has a long and distinguished history in plant genetics. (One plant geneticist, Elliot Meyerowitz, is planned to appear in a future volume.) Geographically, the interviewees are all at American universities - except for Jacob, at the Pasteur Institute in Paris. The rest of the set has an odd west-coast tilt, with a centre of mass at the California Institute of Technology. If this series were your only guide, you might think the eastern seaboard a minor outpost of genetics.

The series does present real diversity of approach, inspiration and influence. Some, such as Herskowitz, Benzer, Hartwell, Witkin and Lewis, were interested in science from a young age, while others, such as Jacob and Rowley, developed their research passions later in life. Rowley and Lindsley were collectors of stamps and butterflies, whereas Benzer and Hartwell were dissectors of radios and frogs. A love of music is a common theme. (Herskowitz's set of scientific adaptations of folksongs, such as, 'I've been workin' on the genome,' is a corny treat.) Rowley's progressive mother insisted that she finish medical school before she got married. Herskowitz's father was a distinguished scientist. Lewis came from a poor family without academic ties. Motulsky relates the harrowing tale of his escape from Nazi Germany in 1939 on the SS St Louis.

The peer-interviewing format - as well as the editing necessary to make each conversation fit onto one DVD - limits these videos' historical value. The interviews contain few segments that will change significantly our understanding of classic experiments. Their pedagogical value, however, is greater. An index of scenes or topics would have greatly aided professors who wish to use clips from the interviews in their courses. Nevertheless, the examples of genetic reasoning, experimental style and scientific inspiration contained in these conversations will be a boon to teachers looking for a fresh way to show their students the ideas, methods and, above all, the joy of science. 